\title{
EFEITO DE DIFERENTES CONCENTRAÇÕES DE AIB E PROCEDÊNCIAS GEOGRÁFICAS NO ENRAIZAMENTO DE ESTACAS DE PARICÁ
}

\author{
EFFECT OF CONCENTRATION OF DIFFERENT IBA AND ORIGINS GEOGRAPHICAL IN \\ PARICA STAKES OF ROOTING
}

\author{
Clenes Cunha Lima ${ }^{1}$ Selma Toyoko Ohashi ${ }^{2}$ Ailton Souza Silveira ${ }^{3}$
}

\begin{abstract}
RESUMO
O objetivo deste trabalho foi determinar a influência da procedência e da concentração do ácido indol-3butírico (AIB) no enraizamento de estacas provenientes de mudas de paricá. As procedências testadas foram: Belém-PA, Tucuruí-PA e Sinop-MT das quais foram obtidas sementes e produzidas mudas para obtenção de estacas. As estacas foram imersas em solução de AIB nas concentrações de 0, 2.000 e 3.000 ppm durante 10 segundos e plantadas em bandejas plásticas contendo vermiculita e fibra de coco como substrato (1:1 $\mathrm{v} / \mathrm{v}$ ). $\mathrm{O}$ delineamento foi inteiramente ao acaso, em esquema fatorial $3 \times 3$ (procedências x concentração de AIB) com quatro repetições e dez estacas por parcela. Após 45 dias foram obtidos dados de percentagem de estacas enraizadas, número médio de raízes, comprimento da maior raiz, percentagem de estacas vivas sem formação de raiz, percentagem de estacas mortas e percentagem de estacas que emitiram brotos. A análise de variância indicou que não houve diferenças estatísticas significativas entre as procedências, porém, para a concentração verificou-se que as soluções a 2.000 e 3.000 ppm foram mais eficientes para enraizamento e desenvolvimento de raiz. A interação indicou comportamento diferencial entre procedências devido à procedência Sinop-MT ter apresentado comportamento inferior na ausência do AIB, contudo, com uma resposta superior às demais procedências quando da aplicação da solução de AIB. Nesse sentido, fazse necessário definir concentrações mais adequadas para o enraizamento de estacas obtidas de diferentes procedências geográficas.
\end{abstract}

Palavras-chave: estaquia; muda; auxina; Fabaceae.

\begin{abstract}
This work aimed at determining the influence of the origin and of the concentration of Indole-3-butyric acid (IBA) over the rooting of paricá cuttings. The origins tested were: Belém (PA), Tucuruí (PA) and Sinop (MT). We obtained seeds from those locations and produced seedlings from which cuttings. The cutting were immersed in IBA solution in the concentrations of 0,2000 and $3000 \mathrm{ppm}$ (parts per million) for 10 seconds and planted in plastic trays containing vermiculite and coconut fiber as substrate $(1: 1 \mathrm{v} / \mathrm{v})$. We employed a fully randomized delineation, in a factorial scheme of $3 \times 3$ (origins $\times$ IBA concentrations) with four repetitions and ten cuttings per part. After 45 days we measured the percentage of rooted cuttings, average number of roots, length of the longer root, percentage of rootless living cuttings, percentage of dead cuttings and percentage of cuttings that produced sprouts. The variance analysis suggested that there were no significant statistical difference between the origins. On the other hand, we verified that the solutions with concentrations of 2000 and $3000 \mathrm{ppm}$ were more efficient for both rooting and root development. The interaction indicated a difference in behavior between the origins, since specimens from Sinop (MT) had lower performance without the IBA, but having a superior response, compared to the other origins, when

1 Engenheira Florestal, MSc., Doutoranda do Programa de Pós-graduação em Biodiversidade e Biotecnologia e Professora da Universidade Federal Rural da Amazônia, PA 275, Km 13, Zona Rural, CEP 68515-000, Parauapebas (PA), Brasil. clenes.cunha@ufra.edu.br

2 Engenheira Florestal, Dr., Professora da Universidade Federal Rural da Amazônia, Av. Tancredo Neves, s/n, Terra Firme, CEP 66077-530, Belém (PA), Brasil. selma.ohashi@ufra.edu.br

3 Extensionista Rural, Empresa de Assistência Técnica Extensão Rural do Estado do Pará, Av. Belém, 16, Santa Maria, CEP 68695-000, Tailândia (PA), Brasil. ailtonssilveira@yahoo.com.br
\end{abstract}

Recebido para publicação em 24/07/2014 e aceito em 5/07/2017

Ci. Fl., v. 28, n. 3, jul. - set., 2018 
immersed in the IBA solution. Therefore, it becomes necessary to define the proper concentrations for the rooting of cuttings coming from different geographical locations.

Keywords: cutting; seedling; auxin; Fabaceae.

\section{INTRODUÇÃO}

O processo de produção de mudas de espécies florestais pode ocorrer através de vias sexuada e assexuada. Este segundo processo, apresenta importância genética quando diz respeito à multiplicação de genótipo altamente heterozigoto, apresentando superioridade em suas características, que se perderiam quando propagadas por sementes (PAIVA; GOMES, 2005).

A partir de características desejáveis, como maior crescimento, melhor qualidade da madeira, brotação vigorosa e resistência a doenças e pragas é possível obter maior produtividade das florestas (SILVA; ANGELI, 2006). Para manter as características nos indivíduos selecionados é necessário o uso da propagação vegetativa, na qual os descendentes apresentam a mesma constituição genética dos indivíduos selecionados de alta produtividade e rápido crescimento, conservando a característica da planta-mãe e maior uniformidade nos plantios (FLORIANO, 2004).

Dentre as técnicas de propagação vegetativa, a estaquia é a mais utilizada para produção de mudas a partir de propágulos vegetativos em larga escala, pois além de manter as características do material genético, diminui o tempo de obtenção das mesmas e possibilita a uniformidade de enraizamento, além de reduzir o período juvenil e, desse modo, promover a antecipação do florescimento (HARTMANN et al., 2002). Entretanto, mesmo nas florestas clonais, em que os indivíduos possuem as mesmas características da plantamãe, podem ocorrer diferenças entre indivíduos da mesma espécie devido às diferenciações existentes entre o ambiente de crescimento do vegetal e ainda devido à própria fase de propagação do material (SILVA; ANGELI, 2006).

Neste aspecto, estudos de enraizamento de espécies de diferentes procedências vêm, há muito tempo, revelando a existência de variações genéticas entre as diferentes origens geográficas e efeitos ambientais sobre o potencial de enraizamento de estacas (COOPER, 1990; TAVARES; PICHET; MASCHIO, 1992; CORREA, 1995; SHIMIZU; SPIR, 1999; KALIL FILHO; HOFFMANN; WENDLING, 2007). Ensaios de procedências são de grande valor por possibilitar conhecer e explorar o potencial das procedências em diferentes condições ambientais e para diferentes finalidades (OHASHI; YARED; FARIA NETO, 2010).

Dentre as espécies florestais utilizadas em diferentes modalidades de plantio no estado do Pará, destaca-se o Schizolobium parahyba var. amazonicum (Huber ex Ducke) Barneby, conhecida como paricá. Esta é uma espécie de rápido crescimento, pouco exigente em adubação e de fácil adaptação em diversos tipos de solo, por isso vem sendo utilizada em larga escala (REIS; LAMEIRA; CORDEIRO, 2007). As pesquisas em propagação vegetativa desta espécie ainda são escassas, com ênfase aos resultados obtidos em pesquisas que encontraram índices significativos de enraizamento de estacas juvenis retiradas das secções medianas e basais da planta e tratadas com concentrações do ácido indolbutírico (AIB) (ROSA; PINHEIRO, 2001). Adicionalmente, pesquisas com cultura de tecidos indicam que a germinação in vitro pode ser uma alternativa para produção de explantes assépticos no processo inicial de micropropagação da espécie (CORDEIRO et al., 2004).

A aplicação de concentrações de AIB é uma técnica auxiliar que pode levar ao aumento da porcentagem de estacas enraizadas, acelerar a iniciação radicial e aumentar o número e qualidade das raízes formadas (FACHINELLO et al., 1995), sendo que a concentração hormonal é variável para cada espécie, clone e estado de maturação do propágulo (GOMES, 1987; WILSON, 1994). Nesse sentido, este trabalho teve por objetivo estudar o efeito da aplicação de concentrações de AIB no processo de enraizamento de estacas provenientes de mudas de diferentes procedências geográficas de paricá.

\section{MATERIAL E MÉTODOS}

Os materiais genéticos utilizados neste trabalho foram obtidos de sementes coletadas em populações naturais ocorrentes em Tucuruí-PA e Sinop-MT e sementes de árvores plantadas no campus da Universidade Federal Rural da Amazônia em Belém, Pará. A localização geográfica (latitude e longitude) e os dados de 
precipitação anual e temperatura máxima e mínima dos locais de coleta estão discriminados na Tabela 1 .

TABELA 1: Caracterização geográfica e climática das procedências das sementes de paricá utilizadas para produção de mudas visando à obtenção de material vegetativo para produção de estacas.

TABLE 1: Geographic and climatic characterization of the origins of parica seeds used to produce seedlings in order to obtain plant material for the production of cuttings.

\begin{tabular}{|c|c|c|c|c|c|c|}
\hline \multirow[t]{2}{*}{ Procedências } & \multirow[t]{2}{*}{ Lat $(\mathrm{S})$} & \multirow[t]{2}{*}{ Long $(\mathrm{O})$} & \multirow[t]{2}{*}{ Alt. (m) } & \multicolumn{2}{|c|}{ Temp $\left({ }^{\circ} \mathrm{C}\right)^{1}$} & \multirow[t]{2}{*}{$\operatorname{Pp}\left(\mathrm{mm} / \mathrm{ano}^{-1}\right)^{1}$} \\
\hline & & & & Mín & Máx & \\
\hline Belém-PA & $01^{\circ} 41^{\prime}$ & $48^{\circ} 43^{\prime}$ & 10 & 29,9 & 31,3 & 3.000 \\
\hline Tucuruí-PA & $03^{\circ} 82^{\prime}$ & $49^{\circ} 67^{\prime}$ & 148 & 25,9 & 26,2 & 2.400 \\
\hline Sinop-MT & $11^{\circ} 98^{\prime}$ & $55^{\circ} 56^{\prime}$ & 371 & 23,1 & 23,2 & 2.200 \\
\hline
\end{tabular}

Em que: ${ }^{1}$ Dados: INMET. Estação mais próxima; Lat $(\mathrm{S})=$ Latitude; Long $(\mathrm{O})=$ Longitude; Alt $(\mathrm{m})=$ Altitude metros; Temp $\left({ }^{\circ} \mathrm{C}\right)=$ Temperatura graus Celsius; $\mathrm{Pp}(\mathrm{mm} / \mathrm{ano})=$ Precipitação Pluviométrica.

As sementes das três procedências foram destinadas à produção das mudas efetuada em sacos de polietileno tendo como substrato terra preta, em uma área com sombreamento de $50 \%$ visando diminuir a insolação e temperatura, uma vez que a produção ocorreu no período de junho e julho, ocasião em que o clima em Belém-PA apresentava-se quente e com menor precipitação.

Após 45 dias da semeadura, ocasião em que as mudas apresentavam em média $18,0 \mathrm{~cm}$ de altura e $5,0 \mathrm{~mm}$ de diâmetro a altura do colo, estas foram destinadas à produção das estacas, as quais foram coletadas da secção basal dos ramos, com tamanho médio de $12 \mathrm{~cm}$ de comprimento e 4,0 $\mathrm{mm}$ de diâmetro, e com dois pares de folhas reduzidos a metade visando manter a fotossíntese e reduzir a transpiração da estaca. $\mathrm{Na}$ base de todas as estacas foi feito um corte em bisel com a finalidade de aumentar a área de absorção do regulador de crescimento, assim como no ápice, para evitar possível excesso de água. Durante o preparo as estacas foram dispostas provisoriamente em um recipiente com água para evitar a desidratação.

Após estarem todas prontas, as estacas foram tratadas com AIB em solução hidroalcoólica (50\%) durante dez segundos e em seguida plantadas em bandejas plásticas contendo vermiculita e fibra de coco $(1: 1 \mathrm{v} / \mathrm{v})$ como substrato, mantidas em uma caixa de enraizamento confeccionada em madeira e revestida com plástico transparente em todos os lados para manutenção da umidade e com isto dar condições favoráveis ao enraizamento das estacas. Na parte superior da caixa, além da cobertura plástica, foi colocado um telado com sombrite a $50 \%$, para que com o sombreamento houvesse diminuição da temperatura.

A caixa de enraizamento foi mantida em casa de vegetação coberta com telhas semitransparentes localizada no Instituto de Ciências Agrárias (ICA) da Universidade Federal Rural da Amazônia (UFRA) Campus Belém. As bandejas plásticas e a caixa de enraizamento foram previamente lavadas e desinfestadas com solução de hipoclorito de sódio $(0,5 \% \mathrm{v} / \mathrm{v})$ e após 15 minutos, lavadas em água corrente.

O delineamento experimental foi inteiramente ao acaso, em esquema fatorial 3 x 3 (procedências e concentrações) com quatro repetições e 10 estacas por parcela. As estacas foram obtidas das procedências Belém-PA, Tucuruí-PA e Sinop-MT e tratadas com as concentrações de AIB 2.000 ou 3.000 ppm e o tratamento testemunha ( $0 \mathrm{ppm})$.

Transcorridos 45 dias do plantio das estacas, avaliaram-se os seguintes parâmetros: percentagem de estacas enraizadas (\%EE), número médio de raízes por estaca (NMR), comprimento da maior raiz (CMR), percentagem de estacas vivas sem raiz (\%EVSR), percentagem de estacas mortas (\%EM) e percentagem de estacas com brotos $(\% \mathrm{~EB})$.

Procedeu-se à transformação dos dados, de forma a garantir os pressupostos de normalidade e de igualdades de variâncias necessários para aplicação da Análise de Variância (Anova). Os valores em percentagem foram transformados através da fórmula arcsen $\sqrt{ } \mathrm{x} / 100$. Os dados de número médio de raízes, comprimento médio da maior raiz e comprimento de broto foram transformados em $V_{x}+1$, em que $\mathrm{x}$ é o valor da variável obtida. As médias foram comparadas pelo teste de Tukey a $5 \%$ de probabilidade. As 
interações significativas foram submetidas à análise de regressão. Todas as análises foram efetuadas usando o software Excel 2007 e o programa estatístico SAEG (Sistema de Análises Estatísticas e Genéticas).

\section{RESULTADOS E DISCUSSÃO}

Pela análise de regressão (Figura 1) é possível observar que ocorreu um aumento linear na percentagem de enraizamento das estacas $(\% \mathrm{EE})$ produzidas das diferentes procedências à medida que aumentou a concentração de AIB, podendo-se observar, que há um baixo percentual de enraizamento de estacas não tratadas com AIB para as três procedências utilizadas.

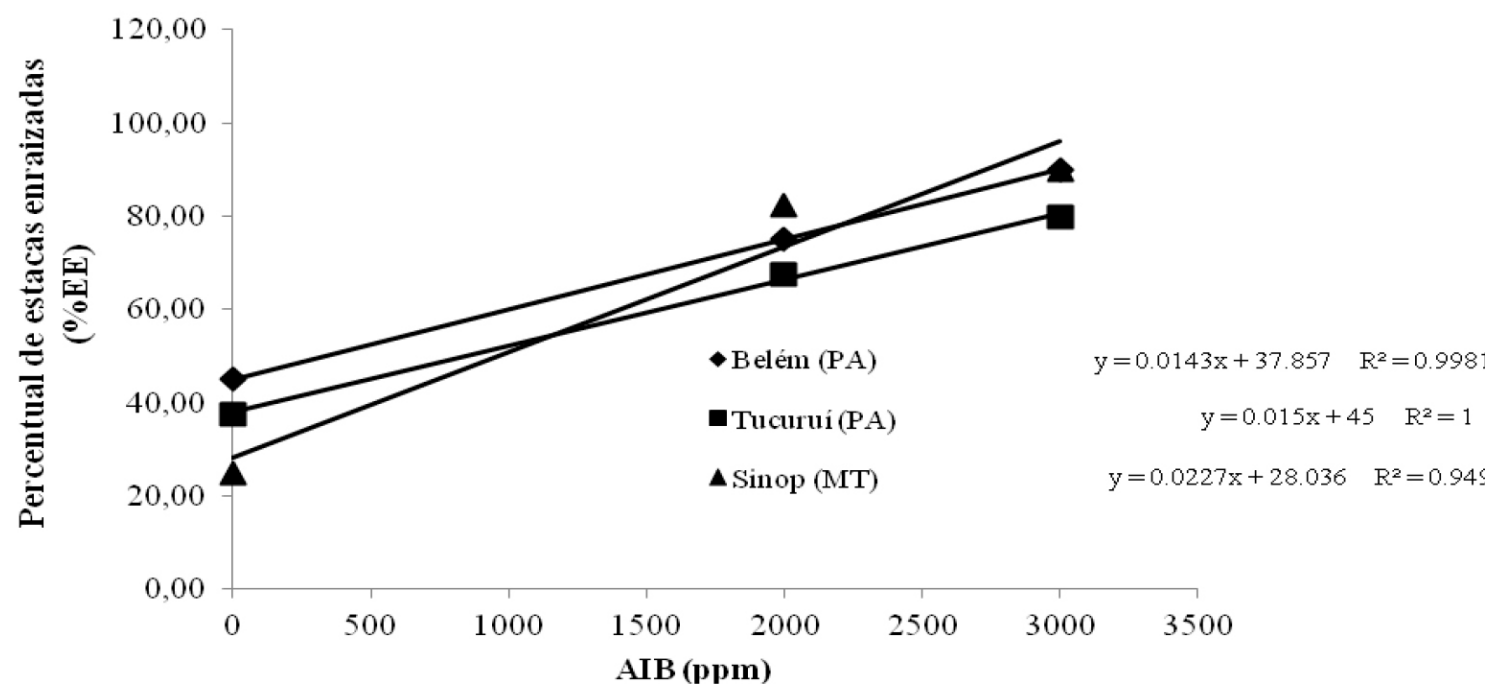

FIGURA 1: Comportamento do enraizamento de estacas produzidas de diferentes materiais genéticos de paricá, 45 dias após o tratamento com concentrações de $\operatorname{AIB}(0,2.000$ e 3.000 ppm).

FIGURE 1: Behavior of stem cuttings produced from different genetic material paricá, 45 days after treatment with IBA concentrations $(0,2,000$ and $3,000 \mathrm{ppm})$.

As procedências não diferiram entre si com médias estatisticamente iguais. Enquanto para o fator concentração de AIB houve influência no enraizamento das estacas, com as concentrações 2.000 e 3.000 ppm, estatisticamente iguais entre si, diferindo do tratamento sem aplicação de AIB (0 ppm). Para a interação houve diferenças estatísticas significativas, com um comportamento diferencial das procedências entre as concentrações estudadas.

Este fato está associado ao comportamento da procedência Sinop, que diferiu estatisticamente da procedência Tucuruí quando ocorreu aplicação de AIB a $2.000 \mathrm{ppm}$. A procedência Belém apresentou resultados intermediários nesta mesma concentração, igualando-se estatisticamente com Sinop e Tucuruí. Nos tratamentos de AIB a 0 e 3.000 ppm, todas as procedências tiveram comportamentos iguais em termos estatísticos.

A taxa de enraizamento total para a interação dos fatores foi de $90,0 \%$, tanto para a procedência Sinop quanto para Belém, nas concentrações 2.000 e 3.000 ppm, respectivamente. A procedência Tucuruí, quando tratada a 2.000 e $3.000 \mathrm{ppm}$ apresentou a menor taxa total de enraizamento $(67,5 \%$ e $80,0 \%$, respectivamente).

Um aspecto importante a considerar, é o fato das estacas terem sido produzidas da secção basal das mudas, logo não apresentavam a gema apical, considerada a principal fonte de acúmulo de auxina endógena nos propagulos e importante no processo rizogênico. Entretanto, para o paricá, propágulos de origem das secções mediana e basal são os mais indicados para obter maior enraizamento das estacas, conforme abordam Rosa e Pinheiro (2001). Portanto, neste trabalho utilizou-se material vegetativo com maior potencial de enraizamento para a espécie em questão.

Para a variável comprimento da maior raiz (CMR), a concentração de AIB influenciou 
significativamente, e mais uma vez, as concentrações 2.000 e 3.000 ppm apresentaram os melhores resultados e as procedências foram estatisticamente iguais entre si. Para a interação, assim como ocorreu para o percentual de estacas enraizadas, as procedências tiveram um comportamento diferencial, com a procedência Sinop apresentando diferenças estatísticas significativas na concentração de 2.000 ppm, em comparação a Belém e Sinop, nesta mesma concentração (Figura 2). Observa-se que há um aumento linear no CMR com o aumento da concentração de AIB e um menor comprimento da raiz nas estacas não tratadas com AIB, para as três procedências utilizadas.

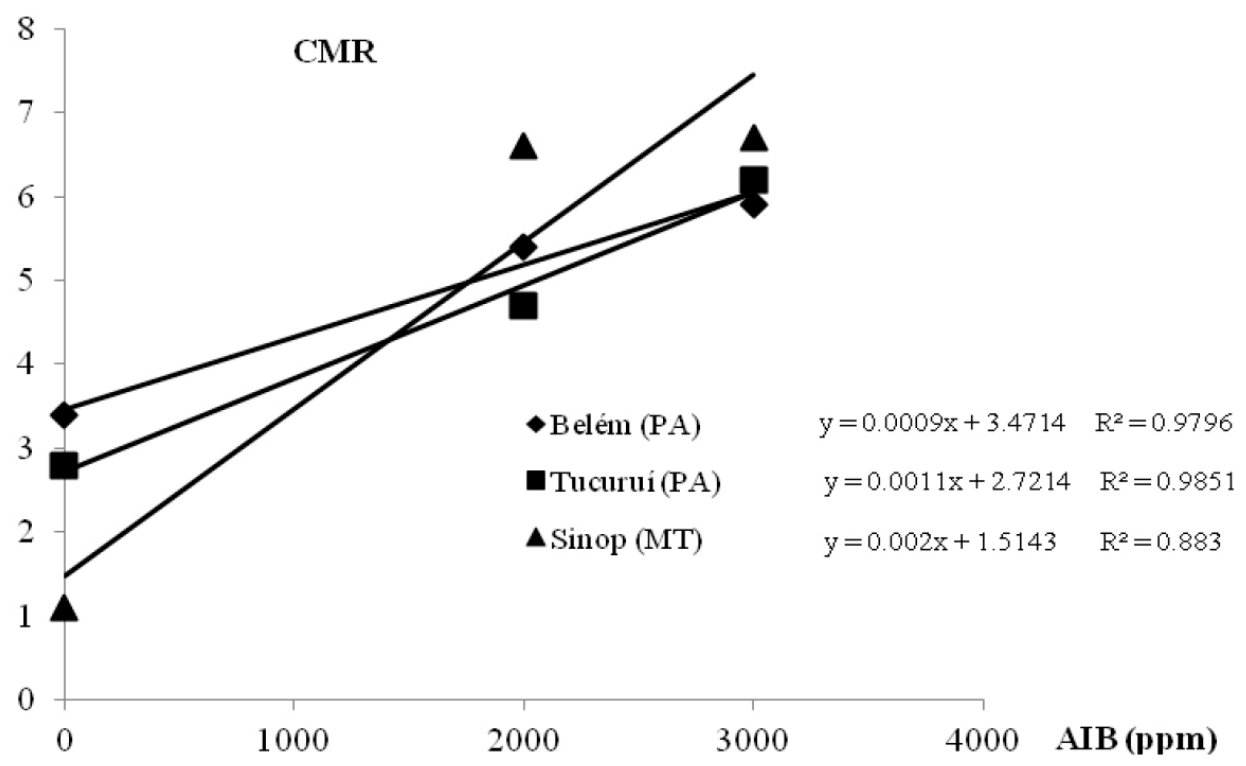

FIGURA 2: Comportamento do comprimento da maior raiz de estacas produzidas de diferentes materiais genéticos de paricá 45 dias após o tratamento com concentrações de $\operatorname{AIB}(0,2.000$ e 3.000 ppm). Dados originais.

FIGURE 2: Behavior of major root length of cuttings produced from different genetic materials paricá, 45 days after treatment with IBA concentrations (0, 2,000 and 3,000 ppm). Original data.

Para o número médio de raízes, a concentração de AIB influenciou no comportamento desta variável (Tabela 2). As concentrações de AIB a 2.000 e 3.000 ppm foram mais eficientes para aumentar a quantidade de raízes, produzindo em média 8,26 e 9,44 raízes por estaca, respectivamente.

TABELA 2: Número médio de raízes (NMR) em estacas provenientes de mudas de paricá, 45 dias após o tratamento com concentrações de $\operatorname{AIB}(0,2.000$ e 3.000 ppm).

TABLE 2: Average Number of roots (NMR) in cuttings from seedlings paricá, 45 days after treatment with IBA concentrations $(0,2,000$ and $3,000 \mathrm{ppm})$.

\begin{tabular}{cc}
\hline AIB $(\mathrm{ppm})$ & NMR \\
\hline 3.000 & $9,44 \mathrm{a}$ \\
2.000 & $8,26 \mathrm{a}$ \\
0 & $2,28 \mathrm{~b}$ \\
\hline Média & 6,66 \\
\hline
\end{tabular}

Em que: DMS = Desvio Médio Significativo (2.71); NMR = Número Médio de Raiz. Médias seguidas de mesma letra na linha não diferem entre si pelo teste Tukey $(\mathrm{P}<0,05)$. Dados transformados $\sqrt{\mathrm{X}}+1$.

Além da percentagem de enraizamento, o número e comprimento de raízes formadas nas estacas são as variáveis mais relevantes na produção de mudas (ANTUNES et al., 1996). Para a sobrevivência de mudas provenientes de propagação vegetativa, o número de raízes na estaca deve ser mais importante do 
que o comprimento das raízes porque, nesse caso, a área de absorção de água e nutrientes é bem maior (BIONDI et al., 2008). Além disso, estacas com raízes maiores têm mais chance de perda ou danos na transposição de mudas para outro recipiente.

Ao serem relacionadas as variáveis comprimento das raízes e número de raízes, enquanto fator relevante na qualidade do sistema radicular, observa-se este comportamento nas estacas de paricá, nas quais a quantidade de raízes formadas foi maior que o tamanho das raízes, atingindo em média 6,66 raízes por estaca com 2,35 cm de comprimento.

Esses resultados demonstraram que as concentrações de AIB foram eficientes para aumentar a taxa de enraizamento e melhorar o sistema radicular das estacas em relação ao número e comprimento de raízes. Vários autores destacam que o emprego de reguladores de crescimento pode tornar mais eficiente a formação das raízes, pois essas substâncias, além de acelerarem o processo de enraizamento, melhoram a qualidade das raízes formadas, produzindo mudas com uniformidade (HARTMANN; KESTER, 1978; ONO; RODRIGUES; RODRIGUES, 1992; FACHINELO; HOFMANN; NACHTIGAL, 1994).

Resultados semelhantes aos encontrados neste estudo foram observados por Bortolini et al. (2009), que obtiveram superioridade no tratamento com $3.000 \mathrm{mg} \mathrm{L}^{-1}$ de AIB com espécies do gênero Tibouchina Aubl, assim como os resultados de Biasi, Pommer e Pino (1997), em que a maior emissão de raízes por estacas de videira foi encontrada com a maior concentração de AIB $\left(2.000 \mathrm{mg} \mathrm{L}^{-1}\right)$ e também Endres et al. (2007) para o percentual de enraizamento de estacas de Caesalpinia echinata. Os autores concluíram que estacas tratadas com $2.500 \mathrm{mg} \mathrm{L}^{-1}$ de AIB se mostraram superiores ao controle. Wendling et al. (2000) também constataram o efeito positivo das concentrações de 1.000 a $3.000 \mathrm{mg} \mathrm{L}^{-1}$ de AIB no processo de rizogênese em miniestacas de Eucalyptus spp.

Em outra dimensão, a literatura aponta que o uso do AIB é dispensável para o enraizamento de propágulos juvenis de espécies florestais obtidos de mudas produzidas por semente, como Calycophyllum spruceanum (GATTI, 2002), Cedrella fissilis (XAVIER et al., 2003), Ilex paraguariensis (WENDLING; SOUZA JÚNIOR, 2003) e Sapium glandulatum (FERREIRA et al., 2010). Os autores enfatizam como causa para esse resultado o alto grau de juvenilidade do material utilizado, no qual o balanço hormonal interno mostrou-se favorável ao enraizamento das estacas.

Gatti (2002), estudando o enraizamento de estacas de teca (Tectona grandis Linn. F.) e de paumulato (Calycophyllum spruceanum (Benth) K. Schum) com o uso de AIB, concluiu que para percentagem de enraizamento das estacas não há necessidade do uso de indutores de enraizamento, no entanto, para estacas de pau-mulato, concentrações de 1.000 e $2.000 \mathrm{ppm}$ antecipam e aumentam o comprimento das raízes. Portanto, a literatura mostra a importância do AIB não apenas para induzir a formação de raízes, mas também como forma de melhorar a qualidade do sistema radicular das estacas.

Considera-se ainda que a qualidade do material genético é fundamental para melhorar o processo de enraizamento, sendo demonstrado que em estacas de Schizolobium amazonicum pode existir comportamento diferencial no enraizamento quanto à origem geográfica dos propágulos vegetativos em decorrência de diferentes concentrações de AIB, podem indicar que estes fatores são dependentes de tal modo que o efeito da seleção do material genético desta espécie, de acordo com as condições geográficas, pode variar em função das concentrações de AIB.

Botezelli et al. (2000) destacam que a procedência das sementes determina as diferenças fenotípicas atribuídas pelas variações ambientais. Deste modo, mesmo sendo de uma mesma espécie, em cada localidade de desenvolvimento da planta-mãe, as sementes estão sujeitas a variações de qualidade fisiológica devido às diferenças edafoclimáticas e outras variantes que acabam por ressaltar certos aspectos de sua composição genética, ou seja, o meio pode ser adequado para expressão de determinadas características que em outro local não se manifestariam.

Neste caso, quando se faz uso de propágulos vegetativos de plantas produzidas através de sementes de diferentes procedências, as características genéticas destas procedências serão transferidas aos seus descendentes. Portanto, o que se tem é uma resposta em função da variabilidade genética e da adaptação edafoclimática das procedências, acarretando manifestações diferentes daquelas que seriam obtidas no seu local de origem.

Desta forma, pode-se inferir, com base nos resultados obtidos neste estudo, que as diferenças no enraizamento das estacas, quando tratadas com as concentrações de AIB podem ser decorrentes das 
variações genéticas e ambientais e ainda da interação genótipo $\mathrm{x}$ ambiente entre as procedências testadas. Entretanto, faz-se necessário o desenvolvimento de novos trabalhos que possam ampliar a amostragem para melhor estudar a variação entre procedências de paricá quanto ao enraizamento de estacas e desta forma obter maiores informações sobre a variabilidade genética na propagação vegetativa do paricá.

De acordo com Schwaegerle (2005), as plantas podem muitas vezes mostrar todo um conjunto de respostas ao enraizamento de estacas que pode variar de forma complexa entre os genótipos. Em relação às condições ambientais, Correa (1995) concluiu que para o enraizamento de diferentes procedências de erva-mate os efeitos ambientais foram preponderantes na manifestação deste caráter, recomendando uma melhoria da metodologia de enraizamento como forma de obter maiores taxas de enraizamento para a espécie.

Cooper (1990), verificando a variação da capacidade de enraizamento de procedências de Eucalyptus dunnii, também observou diferenças entre as procedências utilizadas, com percentagem de enraizamento variando de $20,1 \%$ a $55,8 \%$. O autor evidencia o fator genético dentro desta espécie como mais um parâmetro a ser considerado para a maximização do potencial de enraizamento de estacas.

Assim como Correa (1995), ao estudar o enraizamento de estacas de três procedências de ervamate, em que obteve diferenças significativas para percentual de enraizamento, número de raízes por estacas, número de raízes principais e maior comprimento de raiz, sugerindo a presença de variabilidade genética entre as procedências para essas variáveis. Tavares, Pichet e Maschio (1992) também observaram uma variação na capacidade de enraizamento de 0 a $100 \%$ em materiais de diferentes procedências para a mesma espécie.

Resultados obtidos por Ferreira et al. (2014) ao verificarem o efeito de diferentes ambientes de coleta de estacas de Psychotria nuda para a formação de raízes, demonstraram variações no enraizamento das estacas devido a este fator. Os autores apontam que mesmo se a espécie apresentar alta taxa de enraizamento, a escolha da planta para preparo das estacas é essencial para obtenção de melhores resultados.

Resende e Araújo (1993) destacam que a presença de variabilidade genética permite maior flexibilidade das estratégias de melhoramento na seleção para a característica enraizamento. Deste modo, torna-se importante verificar melhor as diferenças quanto ao comportamento do enraizamento de estacas de procedências de paricá, e com isso, contribuir para um melhor entendimento sobre a variabilidade genética da espécie no que se refere à propagação vegetativa por estaquia, uma vez que a escolha das melhores plantas a partir da sua localização geográfica pode contribuir no processo rizogênico de estacas desta espécie e na formação de mudas vigorosas.

Além disso, é importante que se faça o acompanhamento do desenvolvimento das estacas após o processo de enraizamento, avaliando o seu desempenho quanto aos caracteres de sobrevivência, produção e crescimento da estaca, como forma de obter maiores informações quanto ao comportamento de mudas de paricá produzidas de propágulos provenientes de diferentes procedências.

Para a variável percentagem de estacas mortas (\%EM), não ocorreram diferenças estatísticas entre as procedências e nem entre as concentrações de AIB, porém, ocorreu quando houve interação entre estes fatores. A procedência Sinop apresentou os menores percentuais de mortalidade quando tratadas com 2.000 ppm, diferindo significativamente das procedências Belém e Tucuruí, nesta mesma comparação (Figura 3), pois apresentaram altos percentuais de mortalidade nesta concentração. 


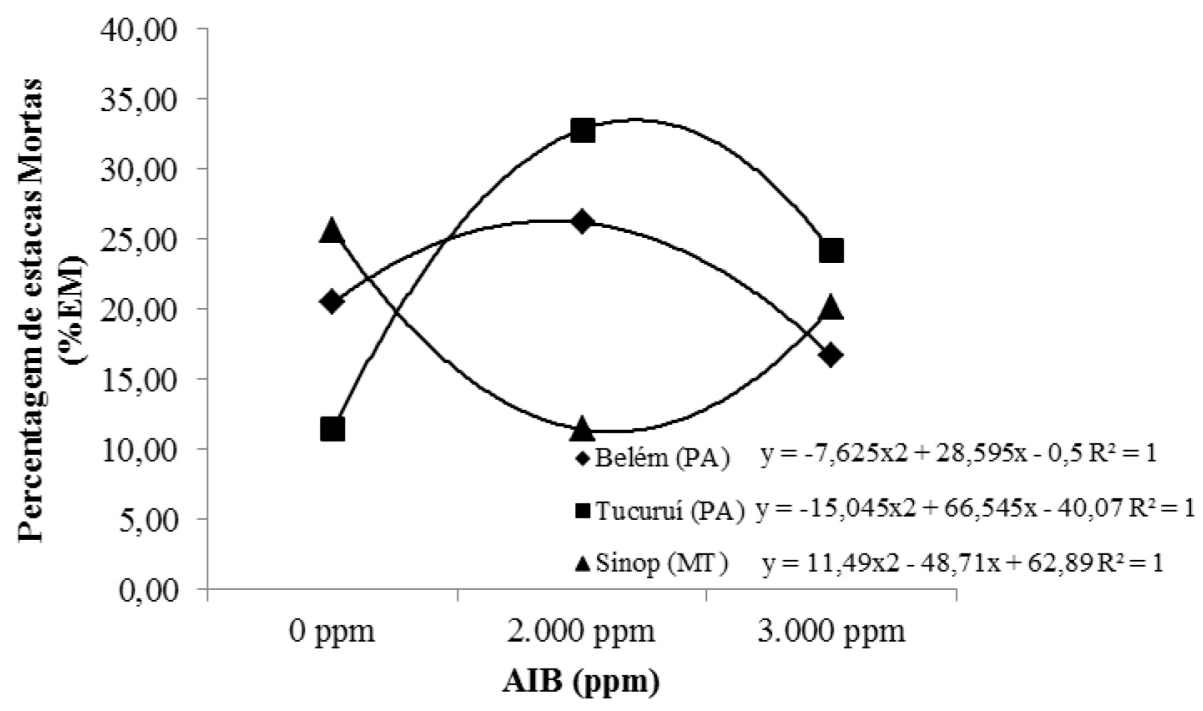

FIGURA 3: Percentagem de estacas mortas (\%EM) provenientes de mudas produzidas de sementes de diferentes procedências de paricá, 45 dias após o tratamento com concentrações de AIB (0, 2.000 e 3.000 ppm).

FIGURE 3: Percentage of dead cuttings (\%EM) from seedlings grown from seeds of different provenances of paricá, 45 days after treatment with IBA concentrations (0, 2000 and 3000 ppm).

Em relação a outros estudos, há evidências diferentes, como os resultados obtidos por Cooper (1990), nos quais não se obtiveram diferenças significativas para o percentual de estacas mortas entre as procedências de Eucalyptus dunnii. A morte das estacas durante o processo de enraizamento em câmara úmida, normalmente, está associada à ocorrência de agentes causadores de podridões, principalmente fungos, e à não formação de raízes, que faz com que ocorra um esgotamento das reservas de nutrientes das estacas (NACHTIGAL, 1999). No entanto, esses fatores são relativamente inerentes às condições de cada experimento. Neste estudo não foi feito controle fitossanitário, o que pode ter contribuído para a morte das estacas.

No teste de comparação de médias para a influência das concentrações de AIB nas variáveis percentagens de estacas vivas e estacas brotadas (Tabela 3), houve diferenças significativas apenas para o fator concentração de AIB. Verificou-se que ambas as variáveis apresentaram melhor desempenho quando não foram tratadas com o AIB (0 ppm), diferindo estatisticamente das duas concentrações utilizadas.

TABELA 3: Percentagem de estacas vivas sem raiz (\%EV) e estacas brotadas (\%EB) provenientes de mudas de paricá, 45 dias após o tratamento com concentrações de AIB ( $0,2.000$ e 3.000 ppm).

TABLE 3: Percentage of rootless cuttings live ( $\% \mathrm{EV})$ and sprouting cuttings (\%EB) from seedlings paricá, 45 days after treatment with IBA concentrations $(0,2,000$ and $3,000 \mathrm{ppm})$.

\begin{tabular}{|c|c|c|}
\hline AIB (ppm) & \multicolumn{2}{|c|}{ Variáveis } \\
\hline & $\% \mathrm{EV}$ & $\% \mathrm{~EB}$ \\
\hline 0 & $44,51 \mathrm{a}$ & $30,11 \mathrm{a}$ \\
\hline 2.000 & $13,83 b$ & $16,68 b$ \\
\hline 3.000 & $12,20 \mathrm{~b}$ & $14,40 \mathrm{~b}$ \\
\hline Média & 23,51 & 20,4 \\
\hline
\end{tabular}

Em que: $\mathrm{DMS}=$ Desvio Médio Significativo; $\% \mathrm{EV}=13,75 ; \% \mathrm{~EB}=13,13$. Médias seguidas de mesma letra na coluna não diferem entre si pelo teste Tukey $(\mathrm{P}<0,05)$. Dados transformados arcsen $\sqrt{\mathrm{x}} / 100$.

Ao se relacionar o percentual de estacas vivas e enraizadas, pode-se considerar que dentre aquelas estacas que não enraizaram na ausência do AIB, representada por um percentual de 36,36\%, existe ainda 
um percentual significativo de estacas vivas $(44,51 \%)$, nesta mesma condição, demonstrando que as estacas responderam positivamente na ausência do AIB, no que diz respeito a manterem-se vivas, independentemente da formação de calos ou não, comparativamente às estacas que receberam aplicações de AIB.

Presume-se, em relação a esse comportamento, que as condições ambientais na caixa de enraizamento foram favoráveis à propagação vegetativa por estaquia de mudas de paricá, mantendo vivas mesmo as estacas que não receberam aplicações exógenas de AIB. Porém, nas concentrações 2.000 e 3.000 ppm, ainda existe 13,83\% e 12,20\%, respectivamente, de estacas vivas. Embora essa variável não garanta um enraizamento futuro, há a possibilidade de ocorrer o processo de formação de raízes nas estacas no decorrer do tempo, pelo fato destas concentrações terem sido as mais eficientes no processo rizogênico, o que sugere a ocorrência de aumento na taxa de enraizamento em estacas provenientes de mudas de paricá com o surgimento dos primórdios radiculares a partir da aplicação destas concentrações.

Para o percentual de estacas brotadas, quando associada esta variável ao percentual de enraizamento, percebe-se uma relação inversamente proporcional, pois, o maior percentual de estacas que brotaram foi observado naquelas que não receberam aplicações de AIB, ou seja, foi maior em estacas com os menores percentuais de enraizamento (Figura 4).

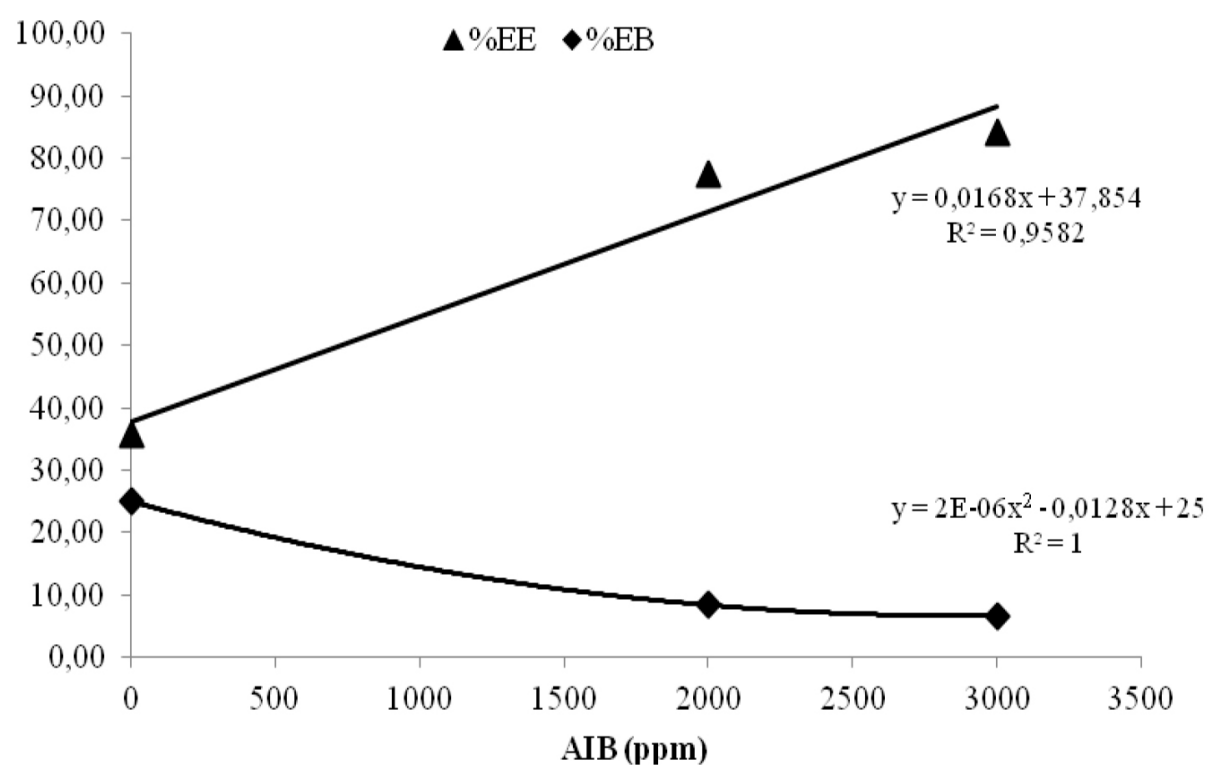

FIGURA4: Comportamento da percentagem de estacas brotadas (EB) em relação à percentagem de estacas enraizadas (EE), obtidas de mudas de paricá, 45 dias após o tratamento com concentrações de AIB $(0,2.000$ e 3.000 ppm). Dados originais.

FIGURE 4: Behavior percentage of sprouting in the percentage (EB) of rooted cuttings obtained (EE) from seedlings paricá, 45 days after treatment with IBA concentrations ( $0,2,000$ and 3,000 ppm). Original data.

Estes resultados inferem que, quanto maior a formação de raiz, menor foi o número de estacas que emitiram brotos. Na concentração 0 ppm, o enraizamento das estacas foi de $35,83 \%$, considerado baixo em relação às outras concentrações, o comportamento foi inverso para a percentagem de estacas brotadas, atingindo o maior percentual de estacas com desenvolvimento de brotos $(25,00 \%)$ nesta concentração, com redução da percentagem após o aumento da concentração.

Em pesquisa realizada por Rosa e Pinheiro (2001), os autores mostraram que as estacas de paricá possuem uma resposta maior ao enraizamento quando do uso de concentrações de AIB. Portanto, considerando que as reservas presentes nas estacas são metabolizadas tanto para o enraizamento quanto para a indução de brotações, sugere-se que as estacas não tratadas com o AIB tiveram maiores chances de metabolizar essas reservas para formação de novas estruturas da parte aérea. Possivelmente, estas relações expliquem o fato da brotação mais intensa ter ocorrido nas estacas que não formaram raízes.

Em estudos de Leão (2003), com a espécie videira também foi verificada essa relação entre estacas enraizadas e estacas brotadas. A autora obteve brotação em todas as estacas, não apresentando resposta ao enraizamento, indicando assim que poderia haver competição da brotação pelos carboidratos 
na estaca que estariam disponíveis para a formação de raízes. Comportamento semelhante também foi encontrado por Leandro e Yuyama (2008) e Bastos (2010), ao estudarem o enraizamento de estacas de Couepia edulis e Spondias sp., respectivamente, em diferentes concentrações de AIB, o número de brotos foi reduzido com o aumento da concentração. No entanto, conforme Bastos (2010), deve-se enfatizar que mesmo ocorrendo brotações nas estacas formadas a partir das reservas orgânicas contidas nas estacas, só haverá o desenvolvimento da parte aérea se houver emissão de raízes adventícias para que haja suprimento nutricional e hídrico.

\section{CONCLUSÃO}

As estacas de paricá têm alto potencial de enraizamento quando tratadas com concentrações entre 2.000 e $3.000 \mathrm{ppm}$ do regulador de crescimento ácido indolbutírico (AIB), devendo-se considerar a importância da relação entre estas concentrações aplicadas em estacas obtidas de material genético de diferentes regiões geográficas. Todavia, sugere-se o aprofundamento das pesquisas para definir as concentrações adequadas às diferentes procedências.

\section{REFERÊNCIAS}

ANTUNES, J. A. S. et al. Efeito do método de aplicação e de concentrações do ácido indolbutírico no enraizamento de estacas semilenhosas de Pyrus calleryana. Revista Brasileira de Fruticultura, Cruz das Almas, v. 18, n. 3, p. 371-376, dez. 1996.

BASTOS, L. P. Caracterização de frutos e propagação vegetativa de spondias. 2010, $53 \mathrm{f}$. Dissertação (Mestrado em Ciências Agrárias) - Universidade Federal do Recôncavo da Bahia, Cruz das Almas, 2010. BIASI, L. A.; POMMER, C. V.; PINO, P. A. G. S. Propagação de porta-enxertos de videira mediante estaquia semilenhosa. Bragantia, Campinas, v. 56, n. 2, p. 367-376, 1997.

BIONDI, D.; BREDOW, E. A.; LEAL, L. Influência do diâmetro de estacas no enraizamento de Tecoma stans (L.) Juss. ex Kunth. Semina: Ciências Agrárias, Londrina, v. 29, n. 2, p. 277-282, abr.jun. 2008.

BORTOLINI, M. F. et al. Enraizamento de estacas caulinares de quatro espécies do gênero Tibouchina Aubl. (Melastomataceae juss.). Revista Brasileira de Horticultura Ornamental, Campinas, v. 14, n. 2 , p. 187-192, 2009.

BOTEZELLI, L. et al. Características dos frutos e sementes de quatro procedências de Dipteryx alata VOGEL (Baru). Cerne, Lavras, v. 6, n. 1, p. 9-18, 2000.

COOPER, M. A. Maximização do potencial de enraizamento de estacas de Eucalyptus dunnii Maiden. 1990, 90 f. Dissertação (Mestrado em Ciências Florestais) -Universidade Federal do Paraná, Curitiba, 1990. CORDEIRO, I. M. C. C. et al. Efeito de BAP sobre a proliferação de brotos in vitro de Schizolobium amazonicum Huber ex Ducke (paricá). Cerne, Lavras, v. 10, n. 1, p. 118-124, jan./jun. 2004.

CORRÊA, G. Controle-genético do enraizamento de estacas de erva-mate (Ilex paraguaríensis Saint Hilaire). 1995. 69 f. Dissertação (Mestrado em Ciências Florestais) - Universidade Federal do Paraná, Curitiba, 1995.

ENDRES, L. et al. Enraizamento de estacas de pau-brasil (Caesalpinia echinata Lam.) tratadas com ácido indol butírico e ácido naftaleno acético. Ciência Rural, Santa Maria, v. 37, n. 3, jun. 2007.

FACHINELLO, J. C. et al. Propagação de plantas frutíferas de clima temperado. Pelotas: UFPel, 1995. $178 \mathrm{p}$.

FACHINELlO, J. C.; HOFMANN, A.; NACHTIGAL, J. C. Propagação de plantas frutíferas de clima temperado. Pelotas: UFPel, 1994. 179 p.

FERREIRA, B. G. A. et al. Miniestaquia de Sapium glandulatum (Vell.) Pax com o uso de ácido indol butírico e ácido naftaleno acético. Ciência Florestal, Santa Maria, v. 20, n. 1, jan./mar. 2010.

FERREIRA, B. G. A. et al. Psychotria nuda (Cham. \& Schltdl.) Wawra: rooting of stock plants in different phenophases and environments. Ciência Florestal, Santa Maria, v. 24, n. 2, p. 367-378, abr./jun. 2014.

FLORIANO, E. P. Produção de mudas florestais por via assexuada. 1. ed. Santa Rosa: [s. n.], 2004. 37 p. (Caderno Didático, 3).

GATTI, K. C. Propagação vegetativa de pau mulato (Calycophyllum sprucanum (Benth) K. Schum.), 
jequitibá (Cariniana estrellensis (Raddi) Kuntze) e teca (Tectona grandis Linn. F.) por miniestaquia. 2002. 83 f. Tese (Doutorado em Ciências Florestais) - Universidade Federal de Viçosa, Viçosa, MG, 2002. GOMES, A. L. Propagação clonal: princípios e particularidades. Vila Real: Universidade de Trás-osMontes e Alto Douro, 1987. 69 p. (Série Didáctica, Ciências Aplicadas, 1).

HARTMANN, H. T. et al. Plant propagation: principles e practices. 7. ed. New Jersey: Prentice Hall, 2002. p. 880.

HARTMAnN, H. T.; KESTER, D. E. Propagación de plantas. México: C.E.C., 1978. 810 p.

KALIL FILHO, A. N.; HOFFMANN, H. A.; WENDLING, I. Propagação vegetativa de liquidambar por enxertia. Colombo: Embrapa Florestas, 2007. 7 p. (Circular técnica, 137).

LEÃO, P. C. S. Utilização de diferentes tipos de estaca na produção de mudas do porta-enxerto de videira, CV. IAC 572 'Jales'. Ciência Rural, Santa Maria, v. 33, n. 1, p. 164-168, jan./fev. 2003.

LEANDRO, R. C.; YUYAMA, K. Enraizamento de estacas de castanha-de-cutia com uso de ácido indolbutírico. Acta Amazônica, Manaus, v. 38, n. 3, p. 421-430, 2008.

NACHTIGAL, J. C. Obtenção de porta-enxertos 'Okinawa' e de mudas de pessegueiro (Prunus pérsica (L.) Batsch) utilizando métodos de propagação vegetativa. 1999. Tese (Doutorado em Produção Vegetal) - Faculdade de Ciências Agrárias e Veterinárias, Universidade Estadual Paulista, Franca, 1999.

OHASHI, S. T.; YARED, J. A. G.; FARIAS NETO, J. T. Variabilidade entre procedências de paricá Schizolobium parahyba var. amazonicum (Huber ex Ducke) Barneby plantadas no município de Colares Pará. Acta Amazônica, Manaus, v. 40, n. 1, mar. 2010.

ONO, E. O.; RODRIGUES, J. D.; RODRIGUES, S. D. Interações entre auxinas e boro no enraizamento de estaca de camélia. Revista Brasileira de Fisiologia Vegetal, Londrina, v. 4, n. 2, p. 107- 112, 1992.

PAIVA, H. N.; GOMES, J. M. Propagação vegetativa de espécies florestais. 3. ed. Viçosa, MG: Ed. UFV, 2005. $46 \mathrm{p}$.

REIS, I. N. R. S.; LAMEIRA, O.A.; CORDEIRO, I. M. C. C. Indução da Calogênese em Paricá (Schizolobium parahyba var. amazonicum (Huber ex Ducke) Barneby) Através da Adição de AIB e BAP. Nota científica. Revista Brasileira de Biociências, Porto Alegre, v. 5, supl 2, p. 501-503, jul. 2007.

RESENDE, M. D. V.; ARAÚJO, A. J. Modelo genético-estatístico para estimação de componentes da variação genética e parâmetros genéticos em testes de progênies com indivíduos repetidos clonalmente. Floresta, Curitiba, v. 3, p. 1-8, 1993.

ROSA, L. S.; PINHEIRO, K. A. O. Propagação vegetativa de estacas de paricá (Schizolobium amazonicum Huber Ex. Ducke) obtidas de material juvenil e imersas em ácido indol-3-butírico. Revista de Ciências Agrárias, Belém, n. 35, p. 79-88, jan./jun. 2001.

SILVA, P. H. M.; ANGELI, A. Implantação e manejo de florestas comerciais. [s. 1.]: IPEF, 2006. (Documentos Florestais, 18).

SCHWAEGERLE, K. E. Quantitative genetic analysis of plant growth: biases arising from vegetative propagation. Evolution, [s. 1.], v. 59, n. 6, p. 1259-1267, 2005.

SHIMIZU, J. Y.; SPIR, I. H. Z. Avaliação de procedências e progênies de liquidambar da América Central, do México e dos Estados Unidos, em Agudos, Brasil. Boletim de Pesquisa Florestal, Colombo, n. 39, p. 93-108, jul./dez. 1999.

TAVARES, F. R.; PICHET, J. A.; MASCHIO, L. M. A. Alguns fatores relacionados com a estaquia da ervamate (Ilex paraguariensis St. Hil.). In: CONGRESSO FLORESTAL ESTADUAL, 7., 1992, Nova Prata. Anais... Santa Maria: Universidade Federal de Santa Maria, 1992. v. 2. p. 626-640.

XAVIER, A. et al. Propagação vegetativa de cedro-rosa por miniestaquia. Revista Árvore, Viçosa, MG, v. 27, n. 2, p. 139-143, 2003

WENDLING, I.; SOUZA JÚNIOR, L. Propagação vegetativa de erva-mate (Ilex paraguariensis Saint Hilaire) por miniestaquia de material juvenil. In: CONGRESSO SUL-AMERICANO DA ERVA-MATE, 3., 2003, Chapecó. Anais... [Chapecó]: EPAGRI, 2003. s. 3-1.

WENDLING, I. et al. Efeito do regulador de crescimento AIB na propagação de clones de Eucalyptus spp. por miniestaquia. Revista Árvore, Viçosa, MG, v. 24, n. 2, p. 187-192, 2000.

WILSON, P. J. The concept of a limiting rooting morphogen in woody stem cuttings. Journal of Horticultural Science, London, v. 9, n. 4, p. 391-400, 1994. 